\title{
Peak expiratory flow in rural residents of Tamil Nadu, India
}

Debidas Ray, Abel Rajaratnam, J Richard

\begin{abstract}
Background In a country such as India that covers several latitudes, climatic zones, ethnic groups, and dietary habits lung function within the normal population would be expected to vary. Several studies have looked at normal values of peak expiratory flow (PEF) in different regions of urban India but none has looked at rural South India. A study of PEF has now been carried out in a rural population of Tamil Nadu.

Methods All subjects were of Dravidian stock and lived at sea level with rice as their staple food. Ten five year age groups from 10 to 59 years with 100 males and 100 females in each were studied. Peak flow was measured by mini-Wright peak flow meter, and height was also measured. Regression equations for predicting normal PEF were calculated.

Results Peak flow ranged from 150 to $6801 / \mathrm{min}$ in males and from 150 to 500 $1 / \mathrm{min}$ in females. Maximum values of PEF were attained at the age of 32.5 years in men and 35.6 years in women. There was a significant linear correlation between height and PEF and a curvilinear relation between age and PEF in both sexes.

Conclusion Regression equations are now available for PEF values in normal subjects from rural South India. PEF was related to age and height and values were greatest in the fourth decade.
\end{abstract}

(Thorax 1993;48:163-166)

The Wright peak flow meter, ${ }^{1}$ introduced in 1959 , is widely used as a simple portable instrument for measurement of ventilatory function and has proved useful for diagnosis and follow up during management of conditions with increased airway resistance, such as asthma, chronic bronchitis, and emphysema. The mini-Wright expiratory flow meter, introduced later, is particularly easy to handle. The performance of the mini-meter is for practical purposes very similar to that of the standard Wright flow meter. ${ }^{2}$

Almost all previous workers in India have reported peak expiratory flow (PEF) measurements in a relatively small number of normal subjects. ${ }^{3-8}$ The workers who carried out the earliest lung function surveys in the Indian subcontinent emphasised the need for standardised values for lung function indices on the basis of ethnic group and environment. ${ }^{9}$ Standardised values for a geographical population should be derived from a sample from that area. ${ }^{10}$ There have been two reports of PEF values in normal subjects in South India, one from Madras city and another from Trichur in Kerala. ${ }^{11}$ Apart from one report on 197 smoking men and another on 108 non-smoking men from farmers in the Punjab, there are no reports on values in a normal population in rural India. ${ }^{12} 13$ The present study was undertaken to establish normal PEF values in inhabitants of rural Tamil Nadu. Regression equations were calculated for predicting normal values of PEF in rural Tamil Nadu.

\section{Subjects and methods}

SUBJECTS

A house to house survey was carried out among the inhabitants of villages in the $\mathrm{KV}$ Kuppam block of the North Arcot district of Tamil Nadu as part of a research project on chronic lung diseases in a rural community. During the survey 2000 normal subjects were selected for the present study. All subjects were of Dravidian stock and lived at sea level with rice as their staple food. The first 100 males and 100 females in each of the five year age groups from 10 to 59 years who fulfilled the criteria for selection were included; thus 1000 males and 1000 females covering 10 age groups were studied in total.

All subjects selected for the study denied a history of smoking or cardiopulmonary disease. They had no skeletal deformity and the women were not pregnant. Specifically the subjects denied any history of frequent or persistent cough and expectoration of sputum, wheeze, or other serious respiratory complaints. They were also free from other significant illness.

\section{MEASUREMENTS}

Measurement of PEF was carried out with a mini-Wright peak flow meter (Airmed, UK). Calibration of the instrument was checked initially and periodically with a standard Wright peak flow meter as reference. Altogether four mini-meters were used. Agreement between the meters was within 20 $1 / \mathrm{min}$ and this was checked on 20 people. All patients were studied by the same observers under a single supervisor (AR). The purpose and technique of the test was explained to subjects in their own language and this was followed by demonstration of the correct 
Table 1 Mean (SD) peak expiratory flow (PEF) and height of 2000 subjects according to five year age groups (100 males and 100 females in each)

\begin{tabular}{|c|c|c|c|c|}
\hline \multirow[b]{2}{*}{ Age (y) } & \multicolumn{2}{|l|}{ Males } & \multicolumn{2}{|l|}{ Females } \\
\hline & $\begin{array}{l}\text { Height } \\
(\mathrm{cm})\end{array}$ & $\begin{array}{l}P E F \\
(l / \mathrm{min})\end{array}$ & $\begin{array}{l}\text { Height } \\
(\mathrm{cm})\end{array}$ & $\begin{array}{l}P E F \\
(l / \text { min })\end{array}$ \\
\hline $10-14$ & $134.05(9.23)$ & $282.3(51.93)$ & $137 \cdot 20(9 \cdot 15)$ & $271 \cdot 1(45 \cdot 35)$ \\
\hline $15-19$ & $156.45(8.94)$ & $395.9(79.91)$ & $150.95(6.42)$ & $327 \cdot 1(55 \cdot 18)$ \\
\hline $20-24$ & $164 \cdot 20(6 \cdot 32)$ & $476 \cdot 1(84 \cdot 84)$ & $152.40(6 \cdot 77)$ & $318.4(63.23)$ \\
\hline $25-29$ & $164 \cdot 70(6 \cdot 82)$ & $470 \cdot 2(81 \cdot 51)$ & $151.00(6.00)$ & $320 \cdot 7(63 \cdot 15)$ \\
\hline $30-34$ & $165.75(6.45)$ & $479.6(82.45)$ & $151 \cdot 10(5 \cdot 02)$ & $322 \cdot 3(57 \cdot 35)$ \\
\hline $35-39$ & $165.35(5.87)$ & $480.7(80.79)$ & $151 \cdot 15(4 \cdot 81)$ & $337 \cdot 7(56 \cdot 28)$ \\
\hline $40-44$ & $165.50(5.50)$ & $447.8(80.06)$ & $152.05(5.36)$ & $334.6(47 \cdot 30)$ \\
\hline 45-49 & $164 \cdot 10(4 \cdot 43)$ & $424.3(90.58)$ & $151 \cdot 70(5 \cdot 25)$ & $319 \cdot 1(57 \cdot 47)$ \\
\hline $50-54$ & $164 \cdot 30(5 \cdot 19)$ & $416.2(63.39)$ & $155.35(7.95)$ & $306 \cdot 2(52 \cdot 35)$ \\
\hline $55-59$ & $163.40(4 \cdot 28)$ & $386 \cdot 1(63 \cdot 80)$ & $151.05(6 \cdot 12)$ & $291 \cdot 0(54 \cdot 58)$ \\
\hline
\end{tabular}

manner of performing the test and several trial attempts. When subjects had understood the technique and were able to perform the test correctly, they were exhorted to make three maximal efforts in the standing position. They were closely observed to ensure that they maintained an airtight seal between their lips and the mouthpiece of the instrument. The highest of the three readings was taken as the final PEF of each subject.

Standing height $(\mathrm{cm})$ was measured without shoes and without traction.

\section{ANALYSIS}

The data were entered into a computer and the Statistical Package for the Social Sciences was used for analysis. The data from men and women were subjected to regression analysis separately by the method of least squares analysis. The linear regression equation PEF $=$ age + a was used to relate PEF and age When multiple $\mathbf{R}^{2}$ (proportion of variations) was very low the higher degree equations were calculated as follows:

$$
\begin{gathered}
y=a+b_{1} \cdot \text { age }+b^{2} \cdot a g e^{2} \\
\text { and } \\
y=a+b_{1} \cdot a g e+b^{2} \cdot a g e^{2}+b^{3} \cdot a g e^{3} .
\end{gathered}
$$

Of the three regression equations, the one that gave the most significant relationship was used. PEF was similarly related to height. When the $R^{2}$ value was very high and no additional improvement was gained no further calculations were made.

For relating both age and height to PEF the equation was as follows:

\begin{tabular}{|c|c|c|c|c|}
\hline \multirow[b]{2}{*}{ Height $(\mathrm{cm})$} & \multicolumn{2}{|c|}{ Males } & \multicolumn{2}{|c|}{ Females } \\
\hline & $n$ & $P E F(l / \mathrm{min})$ & $n$ & $P E F(l / m i n)$ \\
\hline $110-114$ & - & $-\quad-$ & 2 & $210.0(84.85)$ \\
\hline $115-119$ & 5 & $240 \cdot 0(54 \cdot 77)$ & 4 & $245.0(71.41)$ \\
\hline $120-124$ & 13 & $260.8(50.41)$ & 5 & $238.0(40 \cdot 87)$ \\
\hline $125-129$ & 15 & $268 \cdot 7(47 \cdot 79)$ & 6 & $243.3(50 \cdot 07)$ \\
\hline $130-134$ & 27 & $271.9(42.07)$ & 20 & $262.5(35.52)$ \\
\hline $135-139$ & 18 & $288.9(39.54)$ & 40 & $275.0(50.84)$ \\
\hline $140-144$ & 16 & $294.4(49.53)$ & 85 & $300.6(50.36)$ \\
\hline $145-149$ & 31 & $336 \cdot 8(45 \cdot 78)$ & 293 & $311.3(53.01)$ \\
\hline $150-154$ & 50 & $410 \cdot 6(56 \cdot 11)$ & 314 & $323.6(55 \cdot 33)$ \\
\hline $155-159$ & 131 & $430.5(79.62)$ & 154 & $331 \cdot 3(64 \cdot 71)$ \\
\hline $160-164$ & 308 & $434.8(81.41)$ & 50 & $319 \cdot 8(55 \cdot 16)$ \\
\hline $165-169$ & 262 & $452.7(88 \cdot 19)$ & 19 & $346.8(81.04)$ \\
\hline $170-174$ & 89 & $473.8(87.33)$ & 6 & $335.0(66.26)$ \\
\hline $175-179$ & 30 & $508 \cdot 7(72.43)$ & 1 & $280 \cdot 0$ \\
\hline 180 or above & 5 & $544.0(74.03)$ & 1 & $270 \cdot 0-$ \\
\hline
\end{tabular}

$\log _{e}$ PEF $=a \cdot a g e+b \cdot \log _{e}$ age $+c /$ height $+d$.

Table 2 Mean (SD) peak expiratory flows (PEF) in relation to height
The above model was adopted on the assumption that at any given age PEF increases with height whereas there is a decrease in PEF after it has attained a peak in adult life.

\section{Results}

The mean (SD) PEF of subjects in each age and height group are shown in tables 1 and 2 . Values were generally lower in women than in men of the same age. The highest mean PEF values were found in the 35-39 year age group in both men and women; but the regression equations (see below) showed that the maximum PEF was reached at the age of 32.9 years in men and 35.6 years in women. Tall men (height $\geqslant 180 \mathrm{~cm}$ ) had the highest mean PEF, 544 (74.02) litres/min; the highest value among females was seen in those of $160-169 \mathrm{~cm}$. The regression equation in relation to age and height and the significance of the correlations are shown in table 3.

Of the three regression equations given for males relating PEF and age, a third degree curve gave the most significant relationship ( $p$ $<0.001)$. This regression equation explained $94.6 \%$ of the variation in PEF in males. Of the three regression equations for females relating $\mathrm{PEF}$ and age, the second degree curve gave the most significant relationship ( $p$ $<0.01$ ) and explained $74.6 \%$ of the variation in PEF.

The linear regression relationship gave the best fit between PEF and height for both males and females ( $p<0.001$ for both). When both age and height were related to PEF the equations that fitted the data best were:

Men

$\log _{\mathrm{e}}$ PEF $(1 / \mathrm{min})=$

$0.683 \log _{\mathrm{c}}$ age -0.025 age $-186 \cdot 4 /$ height $(\mathrm{cm})+5.72$ Women

$\log _{\mathrm{e}}$ PEF $(1 / \mathrm{min})=$

$0.315 \log _{\mathrm{c}}$ age -0.011 age $-117 \cdot 3 /$ height $(\mathrm{cm})+5.86$

Of the total variation in PEF, only a relatively small part $(45.5 \%$ in men, $12.8 \%$ in women) was accounted for by difference in age and height.

\section{Discussion}

In general PEF is lower in healthy Indians than in Western countries ${ }^{14-17}$ or in Chinese 
Table 3 Regression equations of peak expiratory flows (PEF; l/min) on age (years) and height (cm) for males and females

\begin{tabular}{|c|c|c|c|}
\hline Equation & $\begin{array}{l}R R \\
\text { (multiple } \\
\text { correlation } \\
\text { coefficient) }\end{array}$ & $\begin{array}{l}R^{2} \\
\text { (\% of variance } \\
\text { explained) }\end{array}$ & $p$ \\
\hline \multicolumn{4}{|l|}{ Males } \\
\hline $394.051+0.911$ age & 0.224 & $5 \cdot 0$ & NS \\
\hline $106.794+20.648$ age -0.282 age $^{2}$ & 0.906 & $82 \cdot 1$ & $<0.01$ \\
\hline$-200.055+54.428$ age -1.354 age $^{2}+0.010$ age $^{3}$ & 0.984 & 96.8 & $<0.001$ \\
\hline$-337.845+4.727$ height & 0.975 & $95 \cdot 0$ & $<0.001$ \\
\hline $255.574+3.451$ height +0.028 height $^{2}$ & 0.979 & 96.0 & $<0.001$ \\
\hline \multicolumn{4}{|l|}{$\begin{array}{l}\text { Females } \\
\mathrm{PEF}=\end{array}$} \\
\hline $310.858+0.113$ age & 0.084 & 0.7 & NS \\
\hline $217.596+6.521$ age $-0.092 \mathrm{age}^{2}$ & $0 \cdot 864$ & $74 \cdot 6$ & $<0.01$ \\
\hline $194.793+9.032$ age $-0.171 \mathrm{age}^{2}+0.001 \mathrm{age}^{3}$ & 0.868 & $75 \cdot 4$ & $<0.05$ \\
\hline$-19 \cdot 280+2 \cdot 188$ height & 0.943 & 88.9 & $<0.001$ \\
\hline$-1136 \cdot 572+17 \cdot 172$ height -0.050 height $^{2}$ & 0.967 & 93.5 & $<0.01$ \\
\hline
\end{tabular}

inhabitants of Hongkong. ${ }^{18}$ Our values are closer to those observed in coastal residents of New Guinea, ${ }^{19}$ Bantus, ${ }^{20}$ and other African communities. ${ }^{21}$

Several previous studies on PEF have been carried out in India, including a study on young medical personnel in 1961 by Shah and Mehta ${ }^{3}$ and a study by Singh ${ }^{4}$ in 1967 of comparatively robust naval officers posted to the United Kingdom. In the same year Kamat et $a l^{5}$ reported a study of PEF in 485 apparently normal subjects from Madras city. Subsequently there have been other reports but these have been on relatively few subjects. A study of PEF in 2050 subjects from Kerala was reported in $1978,{ }^{11}$ but only 210 women participated. The studies on smoking and

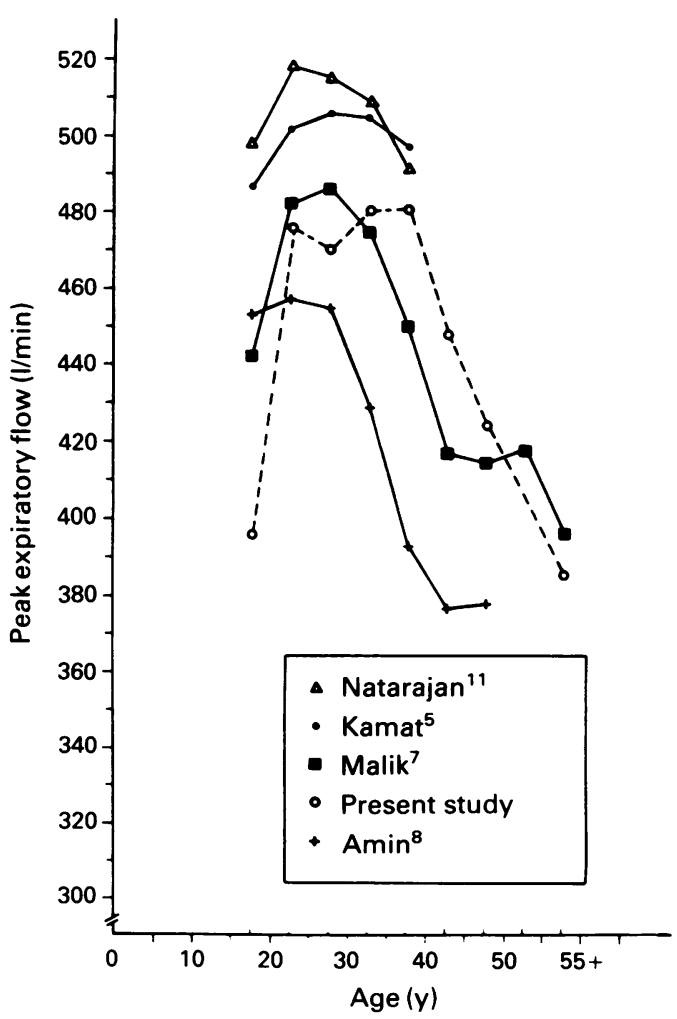

Peak expiratory flow (PEF) according to age in five studies, with high values in the earlier South Indian studies, "similar and intermediate values in the Punjab study ${ }^{7}$ and the present one and lower figures from Baroda, Western India. ${ }^{8}$ non-smoking rural men were from villages in the Punjab but in each study less than 200 subjects were studied. ${ }^{12}{ }^{13}$ There has not to our knowledge been any previous report on PEF from rural Tamil Nadu.

In a study of subjects in Ranipet, near Vellore, ${ }^{22}$ more than two decades ago, the vital capacity of South Indian men was found to be lower than that of their American counterparts. The values in an earlier study, of the Jats of Punjab, ${ }^{23}$ were intermediate between Western figures and those from Ranipet. ${ }^{22}$ This difference was attributed to the difference in climate, ${ }^{22}$ which is hot and humid in Southern India, whereas the Punjab has a temperate climate. A later study of a group of subjects from Delhi ${ }^{24}$ found similar intermediate values. The Ranipet study ${ }^{22}$ consisted of 479 male employees of a factory who were exposed to chemicals and dust, whereas the Punjab study ${ }^{23}$ included only 63 healthy male Jats aged 16-22. The 188 subjects in the Delhi study ${ }^{24}$ came from healthy relations of outpatients, staff members, and students. In our study PEF values were closer to the figures from the Punjab in North India, ${ }^{7}$ higher than the values obtained from Baroda in Western India ${ }^{11}$ and lower than the PEF values for populations of similar age and sex distribution reported earlier from Madras and Kerala in Southern India ${ }^{511}$ (figure 1). In the Kerala study subjects were attending the Medical College exhibition stall during a festival at Trichur, whereas the subjects in the Madras study ${ }^{5}$ were mostly medical students and staff of a general hospital. As the values obtained in the Punjab were lower than those from Madras ${ }^{5}$ Malik et al screened 25 healthy doctors, hospital technicians, and university teachers and found that their mean PEF values were significantly higher than those derived from the regression equation of their main study. ${ }^{7}$ They concluded that the variation was due to changes with time and bias arising from selection of healthy subjects. All our subjects were non-smokers with no respiratory symptoms; otherwise there was no preselection bias. They should be representative of the rural population of Tamil Nadu. They included an equal number of normal men and women from 10 to 59 years of age. 
Almost all previous studies from India have found a positive correlation between height and $\mathrm{PEF},{ }^{811}$ as in our study. A negative linear correlation for age with PEF has also been reported, ${ }^{8}$ as in some Western countries. ${ }^{1425}$ Our study showed a curvilinear relation between age and PEF, as reported from India $^{7}$ and the United Kingdom. ${ }^{16,17} \mathrm{~A}$ linear fall in PEF can occur only after the age at which the maximum PEF is attained, and if children and adults are included in the series the regression will be curvilinear.

Previous studies from India reported the highest PEF values in the age group 25-29 years ${ }^{7}$; but Gregg and Nunn ${ }^{16}$ found that in south west London peak expiratory flow in both sexes began to decline about the age of 35 years. Brooks and Waller ${ }^{17}$ found that the maximum peak flow in men in the United Kingdom was reached at the age of 28 years and a similar age, 27.6 years, was reported by Stebbings ${ }^{26}$ in the United States. The maximum PEF value in our study according to our equations was attained at the age of 32.9 years for men and 35.6 years for women. Younger women from Southern India may be generally weaker before the age of 30 years because of early marriage and frequent childbirth. A curvilinear regression of PEF on age, rising to a maximum at about $30-35$ years, is consistent with increasing body size and muscular power. PEF is influenced by body build and in particular thoracic volume. ${ }^{27}$ The body weight of our subjects was not recorded. The only conveniently measured index of body build is standing height, but this correlates poorly with thoracic volume. This would explain much of the substantial variation in PEF that was not accounted for by differences in age and height.

In a study in Indian children and adults by Gupta and Mathur ${ }^{28}$ age contributed to PEF in addition to height in girls below 16 years and boys below 21 years. In a study of teenagers from Bangladesh drawn from residential colleges 60-100 miles away from Dhaka girls in their early teens had greater mean PEF values than boys, and this was thought to be due to an earlier adolescent spurt in muscle growth and height in girls. ${ }^{29}$ In our study PEF was lower in teenage girls than in teenage boys. This may be due to social attitudes towards girls in South Indian villages, where many girls drop out of school at an early age and thriving is generally harder for them than for boys.

We gratefully acknowledge the financial assistance received from the Indian Council of Medical Research, New Delhi, towards the study and would like to express our appreciation for technical assistance to Mr H Arthur Sadhanandham, Mr R Parandaman, and $\mathrm{Mr} \mathrm{K}$ Jegadeesan and also to $\mathrm{Mr} \mathbf{G}$ Selvakumar for secretarial help.
1 Wright BM, McKerrow CB. Maximum forced expiratory flow rate as measure of ventilatory capacity. $B M^{\mathcal{J}}$ 1959;ii:1041-6.

2 Wright BM. A miniature Wright peak-flow meter. BMF 1978; ii: $1627-8$.

3 Shah JR, Mehta RH. Peak expiratory flow rate as measure of ventilatory capacity. Indian $\mathcal{F}$ Surg 1961;23:397-404.

4 Singh HD. Peak flow rate in Indians. Indian 7 Physiol Pharmacol 1967;11:129-30.

5 Kamat SR, Thiruvengadam KV, Rao TL. A study of pulmonary function among Indians and assessment of the Wright peak-flow meter in relation to spirometry for field use. Am Rev Respir Dis 1967;96:707-16.

6 Gupta S, Puri MB, Singh SI. Pulmonary function test in health. Fournal of the Association of Physicians, India 1975;4:247-52.

7 Malik SK, Jindal SK, Jindal V, Bansal S. Peak expiratory flow rate in healthy adults. Indian $\mathcal{f}$ Chest Dis 1975; 17:166-71.

8 Amin SK, Pande RS. Peak expiratory flow rate in normal subjects. Indian $\mathcal{F}$ Chest Dis Allied Sci 1978;20:80-3.

9 Bhatia SI. The vital capacity of the lungs. Indian Medical Gazette 1929;64:519-21.

10 Williams DE, Miller RD, Taylor WF. Pulmonary function testing in healthy Pakistani adults. Thorax 1978; 37:243-9.

11 Natarajan S, Radha K. Peak expiratory flow rate in normal South Indians. Indian $\mathcal{F}$ Chest Dis Allied Sci 1978;20: 178-82.

12 Malik SK, Singh K. Smoking habits, chronic bronchitis and ventilatory function in rural males. Indian $\mathcal{f}$ Chest Dis 1978;20:73-9.

13 Malik SK, Bunga N. Peak expiratory flow rate in nonsmoking rural males. Indian $\mathcal{F}$ Chest Dis Allied Sci 1978; 20:183-6.

14 Leiner GC, Abramowitz S, Small MJ, Steny VB, Lewis WA. Expiratory peakflow rate. Standard values for normal subjects. Use as a clinical test of ventilatory function. Am Rev Respir Dis 1963;88:644-51.

15 Ferris BG Jr, Anderson DO, Zickmantel R. Prediction values for screening tests of pulmonary function. $\mathrm{Am}$ Rev Respir Dis 1965;91:252-61.

16 Gregg I, Nunn AJ. Peak expiratory flow in normal subjects. $B M F$ 1973;iii:282-4.

17 Brooks AGF, Waller RE. Peak flow measurements among visitors to a public health exhibition. Thorax 1972; 27:557-62.

18 Lam KK, Parg SC, Allan WGL, Hill LE, Snell NJC, Fayers PM, et al. Predictive nomograms for forced expiratory volume, forced vital capacity and peak expiratory flow rate in Chinese adults and children. $\mathrm{Br} \mathcal{F}$ Dis Chest 1983;77:390-6.

19 Woolcock AJ, Colman MH, Blackburn CRB. Factors affecting normal values for ventilatory lung function. Am Rev Respir Dis 1972;106:692-709.

20 Johannsen ZM, Erasmus LD. Clinical spirometry in normal Bantu. Am Rev Respir Dis 1968;97:585-97.

21 Elebute EA, Femi-Pearse D. Peak flow rate in Nigeria. Anthropometric determinants and usefulness in assessment of ventilatory function. Thorax 1971;26:597-601.

22 Milledge JS. Vital capacity and forced expiratory volume one second in South Indian men. Indian $\mathcal{F}$ Chest Dis 1965;7:97-103.

23 Bhattacharya DK. Vital capacity of the Jat males of Punjab. Modification of the formulae existing for its computation. Indian $\mathcal{F}$ Med Res 1963;51:361-5.

24 Jain SK, Ramiah TJ. Normal standards of pulmonary function tests for healthy Indian men $15-40$ years old: comparison of different regression equations (prediction formulae). Indian 7 Med Res 1969;57:1453-66.

25 Pelzer AM, Thomson ML. Expiratory peak flow. BMF $1964 ;$ ii: 123.

26 Stebbings JH Jr. Chronic respiratory disease among nonsmokers in Hagerstown, Maryland, II. Problems in the estimation of pulmonary function values in epidemiological surveys. Environ Res 1971;4:163-92.

27 Nunn AJ, Gregg I. New regression equations for predicting peak expiratory flow in adults. $B M \mathcal{F} 1989 ; 298$ : 1068-70.

28 Gupta CK, Mathur N. Statistical model relating peak expiratory flow rates to age, height and weight in men and women. $\mathcal{F}$ Epidemiol Commun Health 1982;36:64-7.

29 Rahman MA, Ullah MB, Begum A. Lung function in teenage Bangladeshi boys and girls. Respir Med 1990; 84:47-55. 